\title{
Design and Implementation of Multisensory Mirror
}

\author{
T. Gomathi ${ }^{1}$, S. Poonguzhali², L. Megalan Leo ${ }^{3}$, V. Vedanarayanan ${ }^{4}$, A. Aranganathan ${ }^{5}$, \\ Sundara Sandeepteja ${ }^{6}$ and Somu Niroop Rahul ${ }^{7}$ \\ 1,2, 3, 4, 5 School of Electrical and Electronics, Sathyabama Institute of Science and \\ Technology, Chennai, Tamilnadu, India.
}

\begin{abstract}
The primary point of this paper proposes framework to go about as a smart mirror which showcases date, time, climate update can be gathered from web and showed in that brilliant mirror. Today current world, clever framework not just present in the advanced cell and tablet-based Computers. Like that savvy reflect additionally the insightful brilliant framework. This framework is worked with raspberry pi; with Google aide administration it is splendidly reasonable for smart homes. Climate forecasts are removed from the climate cloud they are Providing API for extricating the data. In the event that we request that something mirror it examinations our discourse by utilizing Speech combination module and result gets showed in show behind the mirror. That structured savvy reflect has bit of leeway of little size and not so much weight but rather smaller to utilize and it is appropriate for families. Here every single moment question is looked through utilizing Google aide administration and information is shown on the mirror and furthermore sound input should be possible. There are various engineers and applications that are utilizing the Raspberry Pi for home mechanization. In light of the moderately ease of the Raspberry Pi, this has become a well-known and conservative option in contrast to the costlier business arrangements. Undoubtedly, brilliant mirrors are the reflections of things to come. A piece of the associated reality where we would have the option to see news, temperature, climate and all the more just while glancing and prepping before mirrors. Our proposed framework permits building such mirrors that take into account mirrors to get news on the web and show it on the mirror screen alongside different subtleties.
\end{abstract}

KEY WORDS:SMART MIRROR, RASPBERRY PI, SENSOR, HOME MECHANIZATION, CLIMATE FORECAST.

\section{INTRODUCTION}

In this world everybody should be a solace throughout everyday life. Present day man has developed diverse innovation for the wellbeing of his life. In this day and age, individuals should be associated and they are happy to access to data without any problem. Regardless of whether it is through the TV or web, individuals should be educated and in contact with the present issues occurring far and wide. There has been a consistent and

\section{ARTICLE INFORMATION}

*Corresponding Author: gomes20@gmail.com

Received 13th Oct 2020 Accepted after revision 29th Dec 2020

Print ISSN: 0974-6455 Online ISSN: 2321-4007 CODEN:

$B B R C B A$

Thomson Reuters ISI Web of Science Clarivate Analytics USA and Crossrof Indorod Iournal

$$
\begin{aligned}
& \text { Clarivate } \\
& \text { Analytics }
\end{aligned}
$$

NAAS Journal Score 2020 (4.31)

A Society of Science and Nature Publication,

Bhopal India 2020. All rights reserved.

Online Contents Available at: http//www.bbrc.in/

Doi: http://dx.doi.org/10.21786/bbrc/13.13/45 huge development of utilization of brilliant gadgets in the previous decade. This is because of the development of the business of Internet of Things (IoT). Every day there are an ever increasing number of smart gadgets, vehicles, structures and different articles, which comprise of programming and hardware that are interconnected either by some system or to the Internet. These savvy things have the principle motivation behind gathering and trading information (Pathak et al. 2018). The continually expanding utilization of brilliant interconnected gadgets on a worldwide level, prompted a development of savvy homes as smart innovation environments, whose reason for existing is to facilitate and enhance our everyday exercises. The Internet of Things implies interconnection through the web of registering gadgets implanted in ordinary items, empowering them to send and get information. 
The Internet of Things with its gigantic development broadens its applications to the living condition of the individuals by changing a home to brilliant home. Savvy home is an associated home that interfaces all sort of advanced gadgets to impart each other through the internet. Our way of life has developed so that streamlining time is the most significant thing. Our work depends on the possibility that we as a whole glance at the mirror when we go out, so for what reason wouldn't the mirror become smart (Pathak et al. 2018). A regular methodology for building a smart mirror is to utilize a great single direction glass, a LCD screen, an edge to hold the glass and screen, and an internet browser with python to give the product highlights and drive the display. This task has been created with making home keen to spare time.

The Internet changed our lives by associating us all the more effectively to data and others in the virtual world. The condition of development presently is to give more data less association to get it. The gadget that has been examined and structured is designated "Brilliant Mirror". It is a divider mounted mirror which shows applicable things to the client, for example, climate, time, date, temperature, stickiness and news and different fields of interest Khanna et al. 2017. IoT developed the possibility of remotely observing items through the Internet. With regards to our home, security is pivotal issue to the overall population. For improving the security of home this structure is utilized by proprietor of the house. Accept you are not at home and a cheat enters your home then this system will give an alert through alarm message. At the point when criminal enters the home, PIR sensor will distinguish the development and gives the proprietor ready message. Remote Home security and Home mechanization are the double parts of this undertaking. The at present constructed model of the framework sends alarms to the proprietor over message (Gorden 2017) utilizing the Internet if any kind of human development is detected close to the mirror. Keen mirror is (Athira et al. 2016) a divider mounted mirror which showcases climate, time, news and different regions of interests.

As of late an ever increasing number of gadgets are associated with the web. The web has assumed a significant job in associating an ever increasing number of individuals over the world. Gadgets began to become more brilliant a more brilliant, cell phones became PDAs and in particular web was associated with an assortment of gadgets and the idea came to be known as the 'Web of Things'. Our venture targets investigating different fields where this innovation can be utilized. It targets remembering this innovation for a mirror, in light of the fact that by and large individuals invest a lot of energy before a mirror. We have seen tickers mounted on the divider. Another bit of leeway of this gadget is to give face acknowledgment, which we have done utilizing IOT. This helps the client with security benefits. Savvy mirror can likewise be valuable for getting speedy perspective on your Google takes care of by utilizing face acknowledgment. The savvy mirror would help in creating keen houses by utilizing man-made brainpower lastly finding a spot in enterprises.

Literature Survey: Athira et al. 2016 has developed so that enhancing time is the most significant thing. In light of the client studies and model usage, we present the advancement of a developing apparatus that joins intuitive administrations of data, offered through a UI on the outside of a mirror. Our work depends on the possibility that we as a whole glance at the mirror when we go out, so for what reason don't the mirror become smart. The structure will offer essential administrations, similar to the introduction of customized climate information, time, date and will fuse some extra usefulness, similar to update administration by versatile synchronization and through online networking. Our system depends on identifying nearness of human utilizing Passive Infrared sensors and Wi-Fi availability. When an individual comes before the mirror, it shows the data that is being taken care of from the web. This information or data incorporates schedule, time, climate, news source, warnings, etc. Our structure additionally talks about the discourse acknowledgment and its application in control instrument in home machines and opening and shutting of rack.

Cumeras \&t Khan 2016 clarified about the Internet changed our lives by associating us all the more effectively to data and others in the virtual world. There is no closure of articles that could be made "more brilliant", some being more fit to this than others. Mirrors, for instance, give an enormous surface perfect to showing data and cooperating with. The vast majority have reflected at home so the idea of a keen mirror that you can connect with is alluring and has been fantasized in numerous advanced motion pictures.

Andreu-Cabedo et al. 2015 depicted that the face uncovers the sound status of a person, through a blend of physical signs and outward appearances. The task SEMEOTICONS is interpreting the semeiotic code of the human face into computational descriptors and measures, consequently removed from recordings, pictures, and 3D sweeps of the face. SEMEOTICONS is building up a multisensory stage, as a keen mirror, searching for signs identified with cardio metabolic hazard. The objective is to empower clients to self-screen their prosperity status after some time and improve their way of life by means of customized client direction. Building the multisensory reflect requires dressing huge logical and mechanical difficulties, from touchless information securing, to continuous handling and reconciliation of multimodal information.

Khanna et al. 2017 Interactive processing, with remotely associated implanted gadgets that are being utilized in different everyday exercises, are changing and improving the norms of the personal satisfaction. In view of this intuitive figuring and correspondence advances, numerous gadgets/items are presently developing and with this interactive media knowledge it is giving agreeable, secure and helpful individual administrations 
wherever whether it is home or different The Smart Mirror would help in creating keen houses with installed manmade consciousness, just as discovering its applications in enterprises. In the late 1990s, Eli Zeikha and his group at Palo Alto Ventures introduced a future vision Ambient Intelligence.

Pathak et al. 2018 had direction "smart mirror utilizing raspberry pi" in 2018 In this paper their Design Smart Mirror utilizing raspberry pi with highlights like climate conjecture, News, and by verification an individual it will show the day plans of that individual they propelled utilizing android application refreshing the data of day by day plan's and it will show the updates in that app.

Kumar \& Ramesh 2019 had direction" Raspberry Pi Powered Magic Mirror". The Smart Mirror actualized as a customized computerized gadget furnished with peripherals, for example, Raspberry PI, amplifier, speakers, LED Monitor secured with a sheet of intelligent one way reflect gives one of the most fundamental basic enhancements, for example, climate of the city, most recent updates of news and features and nearby time comparing to the area. Utilizing discourse preparing methods the Smart Mirror in this way associates with the client through verbal orders, capacities and tunes in to the client's inquiry and reacts them satisfactorily.

\section{MATERIAL AND METHODS}

In existing very little effective it can give esteems about time date schedule just and it is perceiving some discourse. However, in proposed technique we interface sensors that sensors likewise give the data about that room. Here we can peruse through voice orders here we envision Google maps numerous highlights accessible. Climate projection status can likewise get refreshed and showed in show screen. Ultrasonic sensor is added for quiet individual to provide order through signal.

Figure 1.1: Overview of The Proposed System

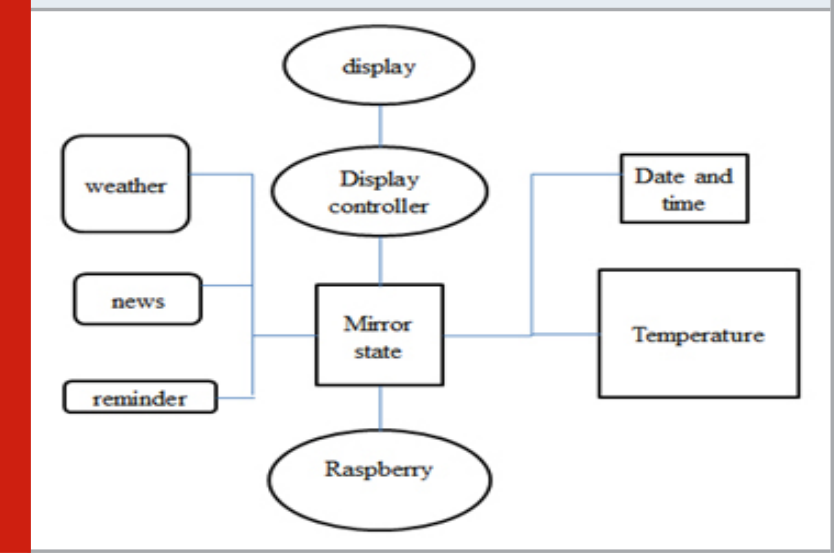

Advantages of proposed system

- This framework is profoundly customized

- It can recognize and welcome every commonplace individual

- Here individual can likewise task like chronicle messages and sending this message as SMS and mail

- Also client can take pictures and send it through mail

- $\quad$ This aide is connected to climate gauging API for getting live meteorological forecast and furthermore climate determining

\subsection{System Design}

1.4.1. Raspberry Pi: This module, Raspberry Pi working framework must be designed in the equipment creation part. When the OS is introduced in the raspberry $\mathrm{Pi}$ equipment we have to send the venture coding for camera commencement, examination, Voice acknowledgment and interfacing Google API. All the product coding and equipment are associated through this Raspberry $\mathrm{Pi}$ Configuration steps.

A Raspberry Pi is a Master card assessed PC at first planned for guidance, energized by the 1981 BBC Micro. Producer Eben Upton's goal was to make a straightforwardness device that would improve programming capacities and gear understanding at the pre-school level. Regardless, because of its little size and accessible worth, it was quickly gotten by tinkerers, makers, and equipment fans for adventures that require more than a principal microcontroller (https://www.researchgate.net/figure/ LBPH-algorithm-flowchart_fig5_3 27980768.)

Raspberry Pi3 model is a Visa estimated single board PC. This board is monetarily adroit when diverged from a certified PC. It is furthermore available as Compute Module Development Kit, which is useful contraption for mechanical applications and has more noteworthy versatility. This fantastic MasterCard estimated single board PC can be used for certain applications. Additionally, it incorporates remote LAN and Bluetooth accessibility making it the ideal response for unfathomable related structures.

LED Monitor: It's a smooth board show, which utilize a variety of light-producing diodes as pixels for a video show. Their splendor permits them to be utilized outside where they are perceptible in the sun store signs and banners, and as of late they have additionally gotten regularly utilized in endpoint signs on open transference vehicles, just as factor message signs on Highways.

Camera: A webcam is a camcorder that feeds or streams a picture or video progressively to or through a PC to a PC arrange, for example, the Internet. Webcams are normally little cameras that sit on a work area, append to a client's screen, or are incorporated with the equipment. Webcams can be utilized during a video visit meeting including at least two individuals, with discussions that incorporate live sound and video. Webcam programming empowers clients to record a video or stream the video on the Internet. As video spilling over the Internet requires a ton of transfer speed, such streams as a rule utilize packed configurations. The greatest goals of a webcam are likewise lower than most handheld camcorders, as higher goals would be decreased during transmission. 
The lower goals empower webcams to be generally reasonable contrasted with most camcorders, yet the impact is satisfactory for video talk meetings.

Ultrasonic Sensor: Ultrasonic Sensors are autonomous solid state contraptions proposed for non-contact identifying of solid and liquid articles. Here we are using Ultrasonic module running HC-SR04 gives $2 \mathrm{~cm}-400 \mathrm{~cm}$ non-contact estimation work, the going accuracy can reach to $3 \mathrm{~mm}$.

LM35 : The LM35 arrangement are accuracy incorporated circuit temperature gadgets with a yield voltage directly corresponding to the Centigrade temperature. The LM35 gadget has a bit of leeway over direct temperature sensors adjusted in Kelvin, as the client isn't required to subtract a huge consistent voltage from the yield to get helpful Centigrade scaling. The LM35 gadget doesn't require any outer alignment or cutting to give run of the mill exactnesses of $\pm 1 / 4^{\circ} \mathrm{C}$ at room temperature and $\pm 3 / 4^{\circ} \mathrm{C}$ over a full $-55^{\circ} \mathrm{C}$ to $150^{\circ} \mathrm{C}$ temperature go. Lower cost is guaranteed by cutting and alignment at the wafer level. The low-yield impedance, direct yield, and exact intrinsic alignment of the LM35 gadget makes interfacing to readout or control hardware particularly simple.

Figure 1.2: Detecting Face using Face Cam

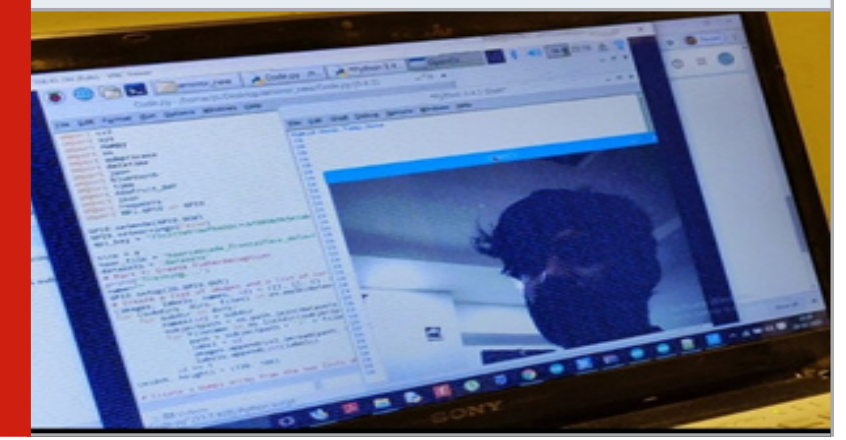

RESULTS AND DISCUSSION

\subsubsection{Detecting Face Using Face Cam}

Initially, we have created a face identification to run the whole software by the authorised/identified person. Once, anyone want to enter into the software, first their face will be detected by the face cam and process further by showing his/her name on the mirror when he/she was an authorized person, otherwise it will be declined.

1.5.2. Voice Commands Through Bluetooth: After the completion of face detection, we have to give voice commands through Bluetooth, based on the voice command it will perform the required operation and gives results.

1.5.2.1. What's The Date: The figure showing the date, when he/she declare the voice command "what's the date" through Bluetooth.

1.5.2.2. What's The Time Now: The above figure showing
Figure 1.3: What's the date

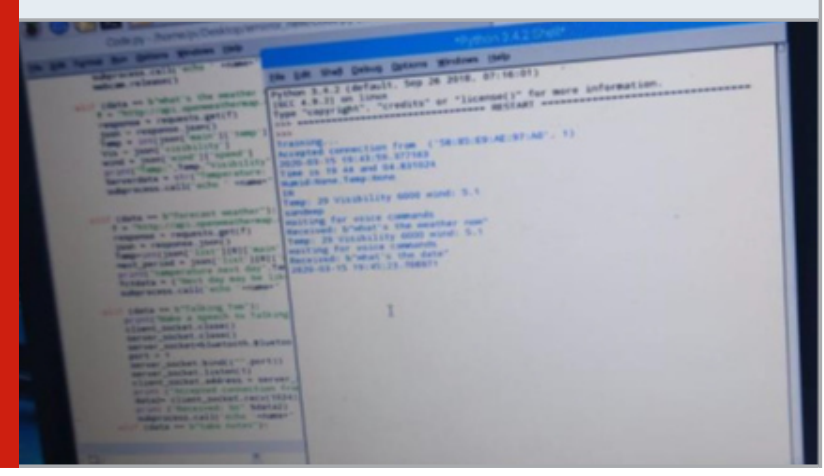

Figure 1.4: What's the time now

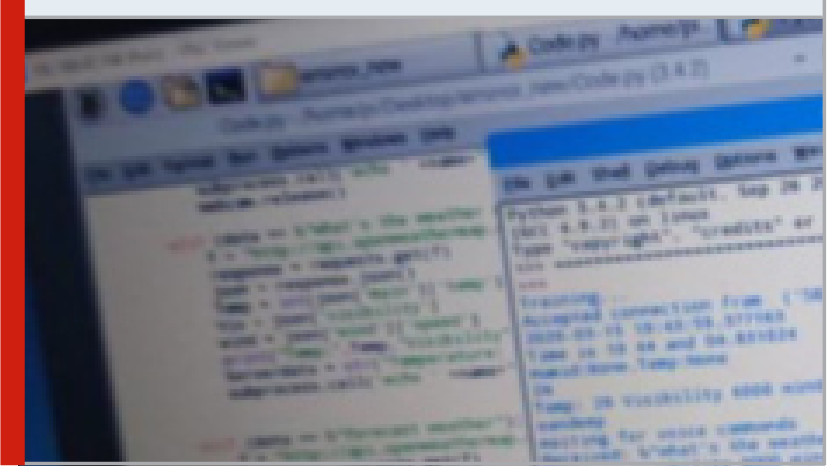

Figure 1.5: What's The Weather Now

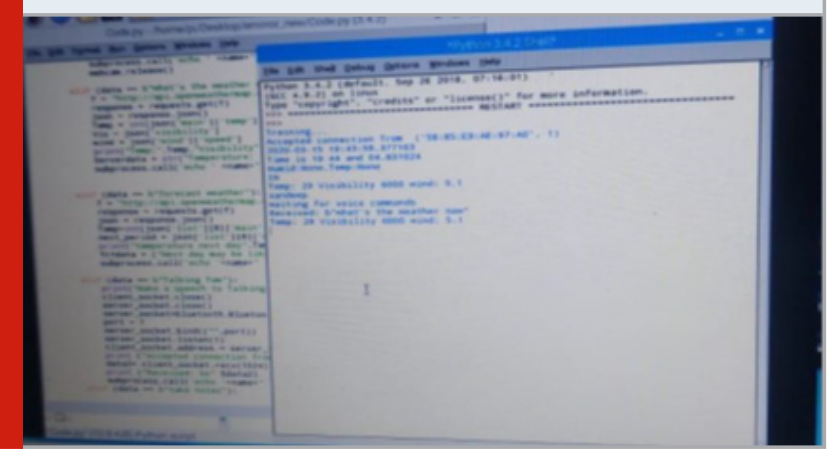

the time, when he/she declare the voice command "what's the time now" through Bluetooth.

The above figure showing the weather, when he/she declare the voice command "what's the weather now" through Bluetooth.

\section{CONCLUSION}

The proposed smart mirror that is actualized by utilizing raspberry pi and scarcely any different sensors is an efficient option in contrast to increasingly costly comparable business items present in the market. Many organizations are utilizing the raspberry pi, web of things and its applications for home robotization. Keen mirrors are a piece of our associated world that shows data identified with individual in the wake of recognizing him. Utilizing programming interface that is associated 
with web it shows climate and other voice orders. Family unit Smart Mirrors: In shopper applications the center capacity is essentially twofold: Be a general educational center point, got from review one's appearance just as expanded with other valuable data and give some style and solace benefits, notwithstanding mirror reflectivity and different capacities. The brilliant mirror created by a host Raspberry Pi - Single load up PC which is associated with the system by means of Wi-Fi, climate data is acquired through API of climate cloud, date, time, schedule that data is shown in the observing presentation unit. The client can associate portable through APP and client can impart through voice blend module. On the off chance that he requests that anything mirror I will react as indicated by the client utilizing Google right hand. Keen mirror plan which has enough favorable circumstances like easy to utilize, ease, little size, easy to understand and it appropriate for family homes.

\section{REFERENCES}

Andreu-Cabedo Y., Castellano P., Colantonio S., Coppini G., Favilla R., Germanese D., Giannakakis G, Giorgi D., Larsson M., Marraccini P., and Martinelli M.: Mirror on the wall... An intelligent multisensory mirror for well-being self-assessment. Published in Multimedia and Expo (ICME), pp. 1-6, (2015).

Athira S., Francis F., Raphel R., Sachin N.S., Porinchu S., and Francis S., Smart Mirror: A Novel Framework for Interactive Display, Published in Circuit, Power and Computing Technologies pp. 1-6, (2016).

Bhoi A. K., Mallick P. K., Liu C. M., \&t Balas V. E.: Bioinspired Neurocomputing, Springer Nature, (2021).

Cumeras i Khan J.: Building a Smart Mirror, Published by U Science Tech, UVIC-UCC in July, (2016).

Giorgi D., Pascali M.A., Raccichini G., Colantonio S., and Salvetti 0.: Morphological analysis of $3 \mathrm{~d}$ faces for weight gain assessment. Eurographics 2015 Workshop on 3D Object Retrieval, Zurich, pp. 55-62, (2015).

Gorden K.S.: Raspberry Pi Powered magic mirror, (2017). https://www.bestbuy.ca/en-ca/product/ logi tech-logitech-hd-webcam-c2 70-960000621/10146689.aspx. https://www.google.com/ imgres?imgurl=https $\% 3 \mathrm{~A} \% 2 \mathrm{~F} \% 2 \mathrm{Fcdn}$.shopif y.com $\%$ 2Fs\%2Ffiles\%2F1\%2F0176\%2F3274\%2Fproducts $\% 2 \mathrm{~F}$ 100437

https://www.researchgate.net/figure/LBPH-algorithmflowchart_fig5_3 27980768.

Khanna V., Vardhan Y., Nair D., and Pannu P.: Design and development of a smart mirror using Raspberry Pi, International Journal of Electrical, Electronics and Data Communication, vol. 5, pp. 63-5, (2017).

Kolar J.S., Farkas L.G., and Munro I.R.: Craniofacial disproportions in apert's syndrome: an anthropometric study. Cleft Palate, vol. 22, (1985).

Kumar G.H., and Ramesh G.P.: Novel gateway free device to device communication technique for IoT to enable direct communication between homogeneous devices. International journal of Pure and Applied Mathematics, vol. 118, pp. 565-578, (2018).

Kumar, H. and Ramesh, G.P., 2019. Reducing power feasting and extend network life time of IoT devices through localization. IJAST, 28, pp.297-305.

Kumbhar P.Y., Mulla A., Kanagi P., and Shah R.: Smart mirror using Raspberry PI. International Journal for Research in Emerging Science and Technology, vol. 5, (2018).

Lee B.J., and Kim J.Y.: Predicting visceral obesity based on facial characteristics. BMC Complementary and Alternative Medicine, vol. 14, pp. 248, (2014).

Lee B.J., Do J.H., and Kim J.Y.: A classification method of normal and overweight females based on facial features for automated medical applications. J Biomed Biotechnol, (2012).

Maheshwari P., Maninder J.K., Sarthak A.: Smart Mirror: A Reflective Interface to Maximize Productivity. Int. J. Comput. Appl. Technol., vol. 166, pp. 30-5, (2017).

Mallick P. K., Balas V. E., Bhoi A. K., and Chae G.-S. (Eds.): Cognitive Informatics and Soft Computing: Proceeding of CISC 2019, Vol. 768, (2020).

Mallick P. K., Balas V. E., Bhoi A. K., and Zobaa A. F. (Eds.): Cognitive Informatics and Soft Computing: Proceeding of CISC 2017, Vol. 768, (2019).

Meng J., and Lin T.: Face Recognition based on Local Binary Patterns with Threshold. pp. 352-356, (2010).

Mishra S., Tripathy H. K., Mallick P. K., Bhoi A. K., and Barsocchi P.: EAGA-MLP-An Enhanced and Adaptive Hybrid Classification Model for Diabetes Diagnosis. Sensors, vol. 20, pp. 4036 (2020).

Mittal D.K., Verma V., and Rastogi R.: A Comparative Study and New Model for Smart Mirror. International Journal of Electrical, Electronics and Data Communication, vol. 5, pp.58-61, (2017).

Nithya V., and Ramesh G.P.: Wireless EAR EEG Signal Analysis with Stationary Wavelet Transform for Co Channel Interference in Schizophrenia Diagnosis. Intelligent Systems Reference Library, vol. 172, pp. 253-265, (2020).

PATHAK A., MISHRA A., SARATE R., BHAVSAR S., and PATEL N.: Smart Mirror Using Raspberry Pi. International Journal of Recent Trends in Engineering \&t Research, vol. 4, pp. 353-8, (2018).

Sun Y., Geon L., and Dan K.: Design of Smart Mirror Based on Raspberry Pi, pp. 77-80, (2018).

Vezzeti E., and Marcolin F.: 3D human face description: landmarks measures and geometrical features. Image and Vision Computing, vol. 30, pp. 698-712, (2012). Yu W., and Chengde L.: Robust Face Recognition and Representation by Non-local Binary Pattern. Journal of Xiamen University (Natural Science), vol. 48, pp. 207-211, (2009). 